\title{
Primary prevention ICD generator at end of life: to replace or not to replace?
}

\author{
Santosh K Padala, ${ }^{\circledR}$ Kenneth A Ellenbogen
}

Implantable cardioverter-defibrillators (ICDs) are the cornerstone of therapy for primary prevention of sudden cardiac death in patients with severely depressed left ventricular ejection fraction (EF) $\leq 35 \%$, irrespective of the aetiology. ${ }^{1-3}$ Current device guidelines and appropriate use criteria lay profound emphasis on the baseline left ventricular EF and New York Heart Association functional class in selecting appropriate candidates for primary prevention ICD implantation. ${ }^{45}$ However, these society guidelines do not provide guidance regarding a decision about replacing ICD generators, especially in patients who have not had any appropriate ICD therapies during the lifespan of the device and/or in whom the left ventricular EF improves to $>35 \%$ at the time of reimplantation. Prior studies have shown that among primary prevention ICD recipients, about $75 \%$ do not experience any appropriate ICD therapies during the lifetime of their first ICD generator ${ }^{6}$ and about 25\%-40\% have improvements in their left ventricular EF $>35 \%$ after ICD implantation. $^{7-12}$ Furthermore, patients requiring generator replacements are older and have significantly greater comorbidities compared with the initial recipients. ${ }^{6} 1314$ A significant proportion of ICD-related procedures in the USA, approximately 40\%, involve ICD generator replacement based on the National Cardiovascular Data Registry data. ${ }^{6}$ Device replacements are associated with substantial healthcare costs and greater risk of major complications compared with initial implant. ${ }^{15} 16$ This raises a critical question as to whether the risk of sudden cardiac death warrants ICD generator replacement in patients who have not had any prior appropriate ICD therapies. Does improvement in left ventricular EF $>35 \%$ lower the risk of sudden cardiac death negating the potential benefits of ICD?

In this issue of the Journal, Looi et $a l^{17}$ report their single-centre outcomes in patients with heart failure after primary prevention ICD generator replacement.

Section of Electrophysiology, Virginia Commonwealth University, Richmond, Virginia, USA

Correspondence to Dr Santosh K Padala, Section of Electrophysiology, Virginia Commonwealth University, Richmond, VA 23284, USA; Santosh.Padala@vcuhealth. org
Of 385 patients with primary prevention ICD/CRT-D (cardiac resynchronization therapy-defibrillator) devices implanted between 2007 and 2015, 61 (16\%) underwent pulse generator replacement. Twenty-one $(34.4 \%)$ patients had a device upgrade. The mean time between the initial implant and generator replacement was 5.8 years. The mean longevity of the device did not differ between the device types (single chamber vs dual chamber vs CRT-D vs S-ICD (subcutaneous-ICD) device; $p=0.24$ ). Patients who presented for generator replacement had a significantly higher left ventricular EF $(31.2 \pm 11$. vs $24.8 \pm 5.2, \mathrm{p}<0.01)$, higher prevalence of diabetes mellitus $(p=0.04)$ and lower mean estimated glomerular filtration rate $(\mathrm{p}=0.02)$. Of 61 patients, $18(30 \%)$ had received prior appropriate ICD therapies. When stratified based solely on left ventricular EF at the time of reimplant, 41 patients $(67 \%)$ met the criterion for device replacement. Twenty patients (33\%) had their left ventricular EF improved $>35 \%$. These patients were more likely to be women, with history of non-ischemic cardiomyopathy, had CRT-D devices, and had higher use of ACE inhibitors/angiotensin II receptor blockers and beta-blockers.

During a mean follow-up period of $1.8 \pm 1.5$ years, 13 patients $(21 \%)$ received appropriate ICD therapies (anti-tachycardia pacing/shock). Among the 20 patients who underwent ICD device replacement despite no longer meeting accepted indications for primary prevention ICD therapy, 10\% (2/20) received appropriate ICD therapies compared with $26.8 \%(11 / 41)$ who continued to meet primary prevention ICD indications. The cumulative risks of appropriate ICD interventions after 1, 3 and 5 years after generator replacement in those who no longer met indications were 0\%, 25\% and $62.5 \%$ and in those who continued to meet primary prevention ICD indications were $3 \%, 28.4 \%$ and $85.9 \%$, respectively (log-rank $\mathrm{p}=0.23)$. Although the authors state that 20 patients did not meet an indication for generator replacement based on improvement in EF, 5 of these patients received appropriate ICD therapy and would likely be considered to have an ongoing indication for secondary prevention ICD.
There were a total of $6(9.8 \%)$ procedure-related complications: 1 haematoma, 1 infection requiring intravenous antibiotics and 4 lead revisions. Half of these complications occurred in patients undergoing device upgrade at the time of generator replacement. A total of 5 patients $(8.2 \%)$ died during follow-up after generator replacement from end-stage heart failure.

There are no randomised controlled trial data on outcomes in patients with primary prevention ICD who are referred for elective generator replacement due to battery depletion and had no appropriate therapies in the past and/or who had improvement in their left ventricular EF. Although a small, retrospective, singlecentre study, the results of the present study adds to the existing knowledge, showing that at the time of reimplant, left ventricular EF as a sole risk marker for assessing future arrhythmic death is far from ideal. ${ }^{17}$ Although the risk of ICD therapies was lower in patients with improved EF $>35 \%$, the cumulative risks of subsequent appropriate ICD interventions did not differ compared with those who continued to have persistently depressed EF $\leq 35 \%$. ${ }^{17}$ The present study, however, was unable to identify predictors that would identify lower risk individuals at the time of reimplant for future ICD therapies.

Few observational studies have analysed the outcomes of primary prevention ICD recipients who were referred for generator replacement and had improvement in the EF > 35\%. . $^{7111218}$ Two large studies are worth mentioning. Madhavan et $a l^{7}$ reported outcomes in 253 primary prevention ICD patients who never received an appropriate ICD therapy and were referred for generator replacement at two tertiary medical centres. EF improved to $>35 \%$ in $28 \%$ of patients at generator replacement. During a median follow-up of 3.3 years after generator replacement, 27\% experienced appropriate ICD therapy. Importantly, patients with EF > 35\% continued to be at a significant risk for appropriate ICD therapy after generator replacement (5\% per year), although at a lower rate than patients with a persistently low EF $\leq 35 \%$ (12\% per year). ${ }^{7}$

In the Sudden Cardiac Death in Heart Failure Trial substudy, 1273 patients with reduced $\mathrm{EF} \leq 35 \%$ assigned to ICD versus placebo were analysed. ${ }^{18}$ During a median follow-up of 30 months, EF improved to $>35 \%$ in about $30 \%$ of patients in each group. Compared with placebo, the adjusted HR for the effect of ICD on mortality was 0.64 (95\% CI 0.48 to 0.85 ) 
in patients with a repeated $\mathrm{EF}$ of $\leq 35 \%$ and 0.62 (95\% CI 0.29 to 1.30 ) in those with a repeated $\mathrm{EF}>35 \%$. These data suggest that patients who had an improvement in $\mathrm{EF}>35 \%$ during follow-up accrued a similar mortality benefit with ICD as those whose EF remained $\leq 35 \% .{ }^{18}$ Similar findings were reported in other smaller studies where improvement in EF $>35 \%$ was associated with lower risk of ICD therapies; however, the residual arrhythmic risk was significant enough to warrant ongoing ICD therapy. ${ }^{9} 11 \quad 12$ Furthermore, heart failure is a progressive disorder. The left ventricular EF may subsequently decline after an initial improvement, thus placing a patient at risk for sudden death if generator replacement is not considered.

We would like to echo the concern raised by the authors of the present study. The fact that the risk of sudden arrhythmic death among those with improved EF and no prior ICD therapies is not zero does not necessarily imply that generator replacement should be performed routinely in all of these patients. The decision to perform a generator replacement should be made after considering carefully the relative balance between competing risks of arrhythmic and non-arrhythmic death. ${ }^{19}$ Compared with an initial ICD implant, patients receiving replacement devices are older, have more significant comorbidities and have shorter life expectancy, all of which may limit the benefit of ICD therapy following generator replacement. ${ }^{19}$ Additionally, generator replacements are associated with significant healthcare expenditure and associated complications, including infection, which may increase the risk of mortality. ${ }^{15} 16$

The present study, along with previously published reports, underscores the limitations of left ventricular EF as a sole marker of future arrhythmic risk. These studies have taught us that patients continue to be at significant risk for ventricular arrhythmias despite improvement in left ventricular EF $>35 \%$. The pivotal randomised controlled trials of primary prevention ICD included only high-risk patients with left ventricular EF $<35 \%$. $^{1-3}$ There has been no randomised controlled trial to date of primary prevention ICD implantation in patients with $\mathrm{EF}>35 \%$. If proven in a prospective study, it will have significant implications on risk stratification in patients with left ventricular EF $>35 \%$. Future prospective studies should also use other markers for better risk stratification, such as detection of myocardial scarring by cardiac MRI in addition to left ventricular EF prior to ICD implantation. ${ }^{20} 21$ In conclusion, it is reasonable to offer generator replacement for primary prevention ICD patients with improved EF $>35 \%$ after carefully considering the risks of arrhythmic and non-arrhythmic death with an individual patient.

Contributors Both authors have contributed equally to the manuscript.

Funding The authors have not declared a specific grant for this research from any funding agency in the public, commercial or not-for-profit sectors.

Competing interests None declared.

Patient consent Not required.

Provenance and peer review Commissioned; internally peer reviewed.

(c) Author(s) (or their employer(s)) 2019. No commercial re-use. See rights and permissions. Published by BMJ.

\section{Check for updates}

To cite Padala SK, Ellenbogen KA. Heart Asia 2019;11:e011167. doi:10.1136/

heartasia-2018-011167

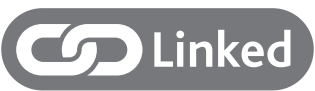

- http://dx.doi.org/10.1136/heartasia-2018-011162

Heart Asia 2019;11:e011167. doi:10.1136/

heartasia-2018-011167

\section{REFERENCES}

1. Moss AJ, Hall WJ, Cannom DS, et al. Improved survival with an implanted defibrillator in patients with coronary disease at high risk for ventricular arrhythmia. Multicenter Automatic Defibrillator Implantation Trial Investigators. N Engl J Med 1996;335:1933-40.

2. Moss AJ, Zareba W, Hall WJ, et al. Prophylactic implantation of a defibrillator in patients with myocardial infarction and reduced ejection fraction. $N$ Engl J Med 2002;346:877-83.

3. Bardy GH, Lee $\mathrm{KL}$, Mark DB, et al. Amiodarone or an implantable cardioverter-defibrillator for congestive heart failure. N Engl J Med 2005;352:225-37.

4. Epstein AE, DiMarco JP, Ellenbogen KA, et al. ACC/ AHA/HRS 2008 guidelines for Device-Based therapy of cardiac rhythm abnormalities: a report of the American College of Cardiology/American Heart Association Task Force on practice guidelines (writing Committee to revise the ACC/AHA/NASPE 2002 guideline update for implantation of cardiac pacemakers and Antiarrhythmia devices): developed in collaboration with the American Association for thoracic surgery and Society of thoracic surgeons. Circulation 2008;117:e350-408.

5. Russo AM, Stainback RF, Bailey SR, et al. ACCF/HRS/ AHA/ASE/HFSA/SCAI/SCCT/SCMR 2013 appropriate use criteria for implantable cardioverter-defibrillators and cardiac resynchronization therapy: a report of the American College of cardiology Foundation appropriate use criteria Task force, heart rhythm Society, American Heart Association, American Society of echocardiography, heart failure Society of America, Society for cardiovascular angiography and interventions, society of cardiovascular computed tomography, and Society for cardiovascular magnetic resonance. J Am Coll Cardiol 2013;61:1318-68.

6. Kremers MS, Hammill SC, Berul Cl, et al. The National ICD Registry report: version 2.1 including leads and pediatrics for years 2010 and 2011. Heart Rhythm 2013;10:e59-65.

7. Madhavan M, Waks JW, Friedman PA, et al. Outcomes after implantable cardioverter-defibrillator generator replacement for primary prevention of sudden cardiac death. Circ Arrhythm Electrophysiol 2016;9:e003283.

8. Zhang Y, Guallar E, Blasco-Colmenares E, et al. Changes in follow-up left ventricular ejection fraction associated with outcomes in primary prevention implantable cardioverter-defibrillator and cardiac resynchronization therapy device recipients. J Am Coll Cardiol 2015;66:524-31.

9. Schliamser JE, Kadish $A H$, Subacius $H$, et al. Significance of follow-up left ventricular ejection fraction measurements in the defibrillators in NonIschemic cardiomyopathy treatment evaluation trial (definite). Heart Rhythm 2013;10:838-46.

10. Schaer B, Theuns DA, Sticherling C, et al. Effect of implantable cardioverter-defibrillator on left ventricular ejection fraction in patients with idiopathic dilated cardiomyopathy. Am J Cardiol 2010;106:1640-5.

11. Naksuk N, Saab A, Li JM, et al. Incidence of appropriate shock in implantable cardioverterdefibrillator patients with improved ejection fraction. $J$ Card Fail 2013;19:426-30.

12. Kini V, Soufi MK, Deo R, et al. Appropriateness of primary prevention implantable cardioverterdefibrillators at the time of generator replacement: are indications still met? J Am Coll Cardiol 2014:63:2388-94.

13. Kramer DB, Buxton AE, Zimetbaum PJ. Time for a change--a new approach to ICD replacement. $N$ Engl J Med 2012;366:291-3.

14. Kramer DB, Kennedy KF, Noseworthy PA, et al. Characteristics and outcomes of patients receiving new and replacement implantable cardioverterdefibrillators: results from the NCDR. Circ Cardiovasc Qual Outcomes 2013:6:488-97.

15. Krahn AD, Lee DS, Birnie D, et al. Predictors of short-term complications after implantable cardioverter-defibrillator replacement: results from the Ontario ICD database. Circ Arrhythm Electrophysiol 2011:4:136-42

16. Poole JE, Gleva MJ, Mela T, et al. Complication rates associated with pacemaker or implantable cardioverter-defibrillator generator replacements and upgrade procedures: results from the replace registry. Circulation 2010;122:1553-61.

17. Looi KL, Gavin A, Cooper L. Outcomes of heart failure patients after primary prevention ICD unit generator replacement. BMJ Heart Asia 2018:doi: 10.1136/ heartasia-2018-011162.

18. Adabag S, Patton KK, Buxton AE, et al. Association of implantable cardioverter defibrillators with survival in patients with and without improved ejection fraction: secondary analysis of the sudden cardiac death in heart failure trial. JAMA Cardiol 2017;2:767-74.

19. Merchant FM, Quest T, Leon AR, et al. Implantable Cardioverter-Defibrillators at End of Battery Life: Opportunities for Risk (Re)-Stratification in ICD Recipients. J Am Coll Cardiol 2016;67:435-44.

20. Klem I, Weinsaft JW, Bahnson TD, et al. Assessment of myocardial scarring improves risk stratification in patients evaluated for cardiac defibrillator implantation. J Am Coll Cardiol 2012;60:408-20.

21. Iles L, Pfluger $H$, Lefkovits $L$, et al. Myocardial fibrosis predicts appropriate device therapy in patients with implantable cardioverter-defibrillators for primary prevention of sudden cardiac death. J Am Coll Cardiol 2011; $57: 821-8$ 